\title{
Cobb-Douglas Function, evaluating the best five active removal methods of space junk
}

\author{
Haowen Zhong \\ School of North China Electric Power University, Baoding 071001, China; 495106868@qq.com
}

Keywords: space junk, Cobb-Douglas Function, short-term model

\begin{abstract}
It's acknowledged that the problem of the scarcity of space resource is getting more and more serious since there is too much space junk floating in the orbits. If orbital debris couldn't be removed in time, there would be a collision between operational spacecraft and orbital debris every 5 to 9 years on average and the situation will go from bad to worse over time. Firstly, this paper picks out five removal methods with the highest feasibility and reliability. These five methods have the ability to clean space junk in different heights near-earth orbit, and in a few years these will become the mainstream methods to make the space cleaning.

Secondly, the article develops a short-term Comprehensive Evaluation Model depended on operations research, economic and risk analysis. It takes Cost, Time and Risk Probabilistic into consideration while calculating the Values. Then the article gets each factor's weight by the Entropy Method and figures out the Values according to the modified Cobb-Douglas Production Function. Since the model uses Negative indicator to calculate but considering that it's widely believed that the higher the Value is, the better. The article takes the reciprocal of the Value as the result. Therefore, we can derive the optimal method to deal with the emergency.
\end{abstract}

\section{Introduction}

At present, there is not a international standard of how to use the resource in space, state organs consider more of their own profits instead of making a harmonious space environment. For example, the 2007 Chinese anti-satellite (ASAT) test produced at least 150,000 pieces of debris in the space. The test illustrates how a single unilateral action in space can be harmful for all space-faring nations and users of satellite services. Therefore, the short-term space cleanup service is provided to deal with some conditions like this.

\section{Model Establishment}

The short-term service (in 30 days) must be evaluated very comprehensively so that we can figure out rigorous and valuable alternatives or combinations of alternatives. Therefore, the article develop a short-term Comprehensive Evaluation Model depended on operations research, economic and risk analysis. In the following article, the model is called short-term model for short.

The article picks out five capturing or removal methods with high feasibility and reliability, which are laser orbital debris removal (LODR), drag augmentation system (DA), electrodynamic tether system (EDT), towboat to capture debris (TCD), net capturing and removal (NCR).

2.1 The short-term space cleanup service

Since the timeliness of customers' requests, the article will use the following three evaluation factors: Cost, Time and Probabilistic Risk while maximizing the Value. Cost means the amount of money during the implementation process of Method A. Time means the minimizing time that Method A will take to meet the customers' requests. Probabilistic Risk means the probability that mission fail while using Method A. These three factors affect each other and we calculate each factor's weight so that to figure out the value of each method.

2.2 The base of the model — the Probabilistic Risk formula based on PRA

The probability of risk is decided by many factors, this article concludes three factors and takes them into account: Fault-Tolerant Rate, Technical Maturity and the longest distance the method can reach. What's more, a correction factor has been proposed to adjust the Probabilistic Risk 
calculation under different business.

The article proposes a creative Probabilistic Risk formula after referring to the principle of PRA and the ideas in risk analysis.

Firstly, after analyzing the chain of the events, it's obvious that the Probabilistic Risk should be index-linked to the Fault-Tolerant Rate and the Fault-Tolerant Rate can be expressed as the ratio of the lost $\mathrm{L}$ and the cost $\mathrm{C}$ and the ratio shall be expressed as exponential. Secondly, the Probabilistic Risk and Technological Maturity is inversely proportional to $\beta$, what means that the more mature the technology is, the lower the risk will be. Thirdly, the Probabilistic Risk is inversely proportional to $\sqrt{D}$ (Distance), that's to say that the longer distance the technology can reach, the lower the risk will be. Last but not least, the Probabilistic Risk is proportional to the Correction Factor.

As a result, the Probabilistic Risk formula can be expressed as

$$
\mathrm{P}=\frac{\xi}{\beta \sqrt{\mathrm{D}}} e^{\frac{\mathrm{L}}{\mathrm{C}}}
$$

The Probabilistic Risk can be calculated according to the formula and each factor's weight can be figured out through a comprehensive consideration of the Cost and Time in 2.1.

Here's the Sheet of Probabilistic Risk

Sheet of Probabilistic Risk

\begin{tabular}{|c|c|c|c|c|}
\hline & Cost $/ \$$ & Lost $/ \$$ & $\begin{array}{c}\text { Fault } \\
\text { Tolerance }\end{array}$ & Distance $/ \mathrm{km}$ \\
\hline $\begin{array}{c}\text { Laser Orbital Debris } \\
\text { Removal (LODR) }\end{array}$ & 4000000 & 500000 & 0.125 & 1200 \\
\hline $\begin{array}{l}\text { Drag Augmentation System } \\
\text { (DA) }\end{array}$ & 5000000 & 820000 & 0.164 & 2000 \\
\hline $\begin{array}{c}\text { Electrodynamic Tether } \\
\text { System (EDT) }\end{array}$ & 7000000 & 1700000 & 0.242857143 & 2000 \\
\hline $\begin{array}{l}\text { Towboat to Capture Debris } \\
\text { (TCD) }\end{array}$ & 11000000 & 600000 & 0.054545455 & 2000 \\
\hline \multirow[t]{2}{*}{$\begin{array}{c}\text { Net Capturing and } \\
\text { Removal(NCR) }\end{array}$} & 15000000 & 4000000 & 0.2666666667 & 2000 \\
\hline & $\begin{array}{l}\text { Technology } \\
\text { Maturity }\end{array}$ & $\begin{array}{l}\text { Correction } \\
\text { Factor }\end{array}$ & $\begin{array}{c}\text { Probabilistic } \\
\text { Risk }\end{array}$ & \\
\hline $\begin{array}{l}\text { Laser Orbital Debris } \\
\text { Removal (LODR) }\end{array}$ & 5 & 0.95 & 0.0062 & \\
\hline $\begin{array}{l}\text { Drag Augmentation System } \\
\text { (DA) }\end{array}$ & 2 & 0.95 & 0.0125 & \\
\hline $\begin{array}{l}\text { Electrodynamic Tether } \\
\text { System (EDT) }\end{array}$ & 3 & 0.95 & 0.009 & \\
\hline $\begin{array}{l}\text { Towboat to Capture Debris } \\
\text { (TCD) }\end{array}$ & 4 & 0.95 & 0.0056 & \\
\hline $\begin{array}{l}\text { Net Capturing and } \\
\text { Removal(NCR) }\end{array}$ & 1 & 0.95 & 0.0277 & \\
\hline
\end{tabular}

Fig.1 Sheet of Probabilistic Risk

2.3 The Establishment of the short-term model

The Sheet of Raw data (Fig.2) refers to papers and 2.2.

\begin{tabular}{|c|c|c|c|}
\hline \multicolumn{4}{|c|}{ Sheet of Raw data } \\
\hline & Cost $/ \$$ & Time/day & Probabilistic Risk \\
\hline Laser Orbital Debris Removal (LODR) & $\begin{array}{l}40000 \\
00\end{array}$ & 5 & 0.0062 \\
\hline Drag Augmentation System (DA) & 5000000 & 20 & 0.0125 \\
\hline
\end{tabular}




$\begin{array}{cccc}\text { Electrodynamic Tether System (EDT) } & 7000000 & 25 & 0.009 \\ \text { Towboat to Capture Debris (TCD) } & 11000000 & 17 & 0.0056 \\ \text { Net Capturing and Removal(NCR) } & 15000000 & 30 & 0.0277\end{array}$

Fig.2 Sheet of Raw data

2.4 The modification of Cobb-Douglas Production Function

The Cobb-Douglas Production Function:

$$
u\left(x_{1}, x_{2}\right)=x_{1}^{c} x_{2}^{d}
$$

In this formula, c and $\mathrm{d}$ are positive number to describe customers' preferences.

Since the article means to draw a conclusion about the feasibility of each method, the article has modified the Cobb-Douglas Production Function in order to figure out the relationship between the feasibility and the factors.

The modified Cobb-Douglas Production Function:

$$
V(\mathrm{C}, \mathrm{T}, \mathrm{P})=C^{x_{1}} T^{x_{2}} P^{x_{3}}
$$

In this formula, the factors $\mathrm{C}, \mathrm{T}, \mathrm{P}$ represent Cost, Time and Risk Probabilistic.

2.5 Model Implementation

Process data in 2.2, Implementation process is as follows:

2.5.1 Use entropy method for data processing

2.5.1.1 standardized processing

Standardized processing to the original data from this formula:

Get a new standardized matrix $X^{\prime}$.

$$
x_{i j}^{\prime}=\frac{\max x_{. j}-x_{i j}}{\max x_{. j}-\min x_{. j}}
$$

\subsubsection{Data Proportion Matrix}

Calculate Proportion Matrix of matrix $X^{\prime}$ by using formula:

Get a new Proportion Matrix Y.

$$
y_{i j}=\frac{x_{i j}^{\prime}}{\sum_{i=1}^{m} x_{i j}^{\prime}}\left(0 \leq y_{i j} \leq 1\right)
$$

2.5.1.3 Calculate index information entropy and information value

Define the Boltzmann constant K:

Calculate index information entropy:

$$
\mathrm{K}=\frac{1}{\ln m}
$$

$$
e_{j}=-K \sum_{i=1}^{m} y_{i j} \ln y_{i j}
$$

Calculate information value:

$$
d_{j}=1-e_{j}
$$

\subsubsection{Calculate Weight}

Calculate index weight:

$$
w_{j}=\frac{d_{j}}{\sum_{i=1}^{m} d_{j}} j=1,2, \ldots, \mathrm{n}
$$

Weights of Impact factors shown in the following sheet:

\begin{tabular}{cccc} 
& Cost $/ \$$ & Time/day & Probabilistic Risk \\
\hline Weights & 0.31757246 & 0.4197464 & 0.262681159 \\
\hline
\end{tabular}

Fig.3 Sheet of Weights

2.5.2 Generalization of Cobb-Douglas Production Function

Use formula of 2.4 to get the final values of five methods: 


\begin{tabular}{cc}
\hline Method & Value \\
\hline Laser Orbital Debris Removal (LODR) & 0.0079 \\
Drag Augmentation System (DA) & 0.0073 \\
Electrodynamic Tether System (EDT) & 0.0065 \\
Towboat to Capture Debris (TCD) & 0.0057 \\
Net Capturing and Removal(NCR) & 0.0051
\end{tabular}

\section{Summary}

1. According to the result of , the final values of five methods are not much difference, indicating that five different cleaning method has its merit and all of them have strong practicability in aerospace.

2. Laser Orbital Debris Removal (LODR) has the max final value, indicating that LODR is optimum method in emergency circumstances.

3. The results also indicate that timeliness dominate mostly and factor time has a bigger weight, it is consistent with the qualitative analysis results.

\section{References}

[1] Leonard Vance ,Allan Mense. Value analysis for orbital debris removal

[2] M. Andrenucci, P. Pergola, A. Ruggiero. Active Removal of Space Debris

[3] Jing Liu. Space debris collision probability and its sensitivity analysis 